\title{
JANELAS DA QUARENTENA: EXPERIÊNCIAS LATINO-AMERICANA DE FORMAÇÃO ENTRE DOCENTES DO BRASIL E PERU
}

\author{
MaIrCe da Silva AraúJo \\ DANUSA TEDERICHE BORGES DE FARIA \\ Jane Marchon Cordeiro Celestino \\ ROBERTA DIAS DE SOUSA \\ Universidade do Estado do Rio de Janeiro (UERJ), São Gonçalo, Rio de Janeiro, Brasil
}

\begin{abstract}
RESUMO: O presente artigo tem como objetivo problematizar os impactos do contexto pandêmico, em curso, sobre as políticas e práticas educacionais, a partir das narrativas de coletivos docentes de dois países articulados por um projeto de pesquisa que tem como aporte teórico-metodológico os referenciais da investigação-formação. Colocando-se no campo da investigação narrativa, a pesquisa busca a construção de um conhecimento com os/as docentes, que se configure tanto como um processo de investigação quanto um processo de formação. O diálogo com as narrativas docentes, à luz das reflexões teóricas, em especial na interlocução com Freire, apontou, para nós, a urgência de se pensar a escola na perspectiva da humanização, além de trazer contribuições para pensarmos a formação de professores/as que se potencializa nos coletivos docentes e nos processos entre pares.
\end{abstract}

Palavras-chave: Narrativas. Professoras. Isolamento.

Manual de instruções

Sentada na minha cama, pernas cruzadas, a luz do sol entra pela janela entrecortada pela grade.

Quantas coisas eu poderia e queria estar fazendo agora. Mas, ficar em casa é o dever que me guia para a minha proteção e a dos outros.

Um turbilhão de sentimentos surge, mas ao que me apego é a decepção. Na humanidade Nas pessoas No futuro No presente $\mathrm{Na}$ escola

Não a escola que conhecemos, com suas possibilidades e impossibilidades, dentro e pela qual lutamos, cotidianamente, por uma educação mais justa. 
A escola que construímos junto com Amanda, Daniel, Phellipe, Martinha, André, Regina, Ruttyê e Isabele e tantas/os outros/as docentes.

A escola que me decepciona, mostrou sua face mais assustadora em 2020: priorizar "conteúdos curriculares" sobre conteúdos de vida; contabilizar dias e horas letivos ao invés de buscar conhecer e acolher experiências e sentimentos. basear o processo pedagógico em atividades virtuais e desconsiderar a importância do afeto.

Quando vejo famílias e docentes questionando a falta de avaliações durante a quarentena, eu me pergunto, em que momento resolvemos colocar nossos corações e nossa alma nos armários de ferro de nossas salas de

aula?

Ou quem sabe em nossas geladeiras. Quando foi que deixamos de nos preocupar e nos importar com o outro, com vidas com histórias e amores?

Se fossemos aprender a ler por meio das palavras desse "novo mundo", hoje, provavelmente, só estaríamos habilitados a decodificar manuais de instruções. Frios, diretos, objetivos e nem sempre dando a instrução correta. Precisamos repensar a vida e a nossa própria humanidade, E, se um vírus mortal, que parou o mundo, ainda não foi capaz de nos provocar a essa reflexão, o que será, então? (Diário da quarentena de Roberta; abril de 2020).

Sob o impacto do chamado à reflexão de Roberta, iniciamos o presente artigo, que tem como objetivo problematizar os efeitos do contexto pandêmico, em curso, sobre as políticas e práticas educacionais, a partir das narrativas de coletivos docentes de dois países articulados por um projeto de pesquisa que tem como aporte teóricometodológico os referenciais da investigação-formação.

Colocando-se no campo da investigação narrativa, a pesquisa em tela busca a construção de um conhecimento com as/os docentes, que se configure tanto como um processo de investigação quanto um processo de formação.

O diálogo com as narrativas docentes, à luz das reflexões teóricas, em especial na interlocução com Freire, apontou, para nós, a urgência de se pensar a escola na perspectiva da humanização, além de trazer contribuições para pensarmos a formação de professores/as que se potencializa nos coletivos docentes e nos processos entre pares.

No desenvolvimento da problemática, organizamos o texto em três seções: começamos trazendo uma contextualização da pandemia no Brasil, seguida de uma apresentação do projeto de pesquisa e dos aportes teórico-metodológicos que 
ARAúJO, M. da S.; FARIA, D. T. B. de; CELESTINO, J. M. C.; SOUSA, R. D. de.

sustentam nossas ações investigativo-formativas; na segunda parte, colocamos em diálogo as narrativas docentes produzidas no projeto à luz das reflexões teóricas, e, por fim, trazemos algumas conclusões, de caráter provisório, possibilitadas pela investigação, que reafirmam a importância de ouvirmos as vozes docentes no enfrentamento dos desafios que o cotidiano nos coloca.

TRANCAFIADAS/DOS EM CASA E DESAFIADAS/OS A REPENSAR A VIDA, A ESCOLA, A HUMANIDADE....

E se um vírus mortal, que parou o mundo, ainda não foi capaz de nos provocar a pensar sobre nossa própria humanidade, o que será, então?

A pergunta de Roberta se soma a tantas outras questões que têm nos atravessados, cotidianamente, enquanto buscamos meios de compreender e construir experiências e respostas criativas e potencializadoras em meio ao turbilhão do que tem sido chamado de "novo normal". Trancafiadas em nossas casas (aqueles/as que podem, que têm casa...), olhando através das janelas físicas e virtuais, encontramo-nos, primeiramente, perplexas/os.

As imagens que vemos nas telas das televisões, computadores, tablets, smartfones, nos levam a perguntar, por vezes, se não estaríamos vivendo um dos filmes de Stanley Kubrick ${ }^{1}$, que, até recentemente, nos provocava sustos e reflexões profundas nas salas de cinema. Essas salas, hoje totalmente fechadas, demarcadas como um dos lugares com maior risco de contaminação.

Perdidas entre a ficção-realidade, lembramo-nos da pergunta de Garcia (2003): "E não tem sido tantas vezes a arte a anunciar o que a ciência vem mais tarde a descobrir?" (p. 197). Parece que a ciência é mais lenta que a arte. Além disso, somente confrontadas por um vírus invisível, começamos a nos dar conta da fragilidade da raça humana no Planeta Terra, apesar das tantas denúncias que ouvimos cotidianamente, como nos alerta Santos (2020):

\footnotetext{
Segundo a Organização Mundial de Saúde a poluição atmosférica, que é apenas uma das dimensões da crise ecológica, mata anualmente 7 milhões de pessoas. Segundo a Organização Mundial de Meteorologia, o gelo da Antártida está a derreter seis vezes mais rapidamente do que há quatro décadas, e o gelo da Groelândia, quatro vezes mais rapidamente do que se previa. Segundo a ONU, temos dez anos para evitar a subida de 1,5 graus de temperatura global em relação à época pré-industrial, e em qualquer caso vamos sofrer (pág. 20).
}

Podemos nos perguntar se tanto o desastre ecológico, anunciado/denunciado exaustivamente nas últimas décadas, quanto a tragédia provocada pela pandemia da Covid-19 não seriam crises que se articulam entre si?

Entendemos, junto com outros autores (SANTOS, 2020; FRIGOTTO, 2020), que a articulação das crises ecológica e pandêmica tem origem na opção por um modelo social de Estado que não gere, de forma sustentável, os recursos provenientes da natureza e nem garante direitos básicos à população (saúde, saneamento básico, água, energia, educação). A crise humanitária, provocada pela Covid-19, desvelou ao mundo o 
que, até então, estava escondido na fumaça cinzenta das ações dos governos capitalistas: colocar o mercado e o lucro em primeiro lugar e excluir as camadas populares dos direitos inerentes à cidadania. Vemos, hoje, Estados Neoliberais, como o Brasil, que entendem os custos sociais como despesas e não como atendimento a direitos, ignorarem protocolos e orientações dos Organismos Mundiais de Saúde e deixarem a população, especialmente as/os mais pobres e vulneráveis, entregue à própria sorte.

Entender a pandemia do coronavírus a partir de um modelo social, que, nos últimos quarenta anos, tem no neoliberalismo a versão dominante do capitalismo, é uma questão crucial para entendermos o que estamos atravessando. Várias análises têm apontado que a opção neoliberal tem deixado os "Estados sem capacidade efectiva para responderem eficazmente à crise humanitária que se abateu sob os seus cidadãos. A fractura entre a economia da saúde e a saúde pública não podia ser maior" (SANTOS, 2020, p. 24).

E como chegamos a essa fragilidade do Estado brasileiro para responder aos impactos da pandemia? Priorizando os princípios do mercado e do lucro máximo para os investidores, a lógica neoliberal colocou em segundo plano o Estado e a garantia dos direitos sociais: de um lado, a privatização dos bens sociais coletivos, tais como a saúde, a educação, a água, a luz, os serviços de correios, dentre outros; de outro, os projetos que retiram os direitos dos trabalhadores: a reforma da previdência, reforma trabalhista, as emendas constitucionais que estabelecem limites para os gastos públicos na saúde e na educação. Paralelamente ao crescimento das parcerias público-privadas, quase sempre um mecanismo de transferência de recursos públicos para o setor privado.

Importante lembrar que as contas da fragilidade do Estado para enfrentar a situação não é distribuída democraticamente, são as/os mais pobres e vulneráveis, as/os que são ainda mais afetadas/os: as mulheres vítimas da violência doméstica, as/os trabalhadoras/es informais (cada vez mais numerosas/os), a população de rua, as/os moradoras/es das periferias e favelas, as/os idosas/os, as crianças, dentre outras/os.

Em síntese, o isolamento social provocado pela pandemia não só torna mais visíveis como reforça a injustiça, a discriminação, a exclusão social e o sofrimento das/dos mais vulneráveis.

É dentro desse contexto que retomamos nosso diálogo com a narrativa da qual abrimos este artigo. A decepção/indignação de Roberta, uma professora da Educação Infantil, com o modelo de escola que começa a se fortalecer, a partir dos impactos provocados pelo isolamento social, nos convida a trazer a discussão para o campo da educação e das práticas que se instauraram no contexto da pandemia.

Qual o papel da escola nesse contexto? Qual a importância dos conhecimentos disciplinares para o modelo de escola e educação nos quais acreditamos? Que outras compreensões sobre a vida, a sociedade e a escola, a pandemia pode nos trazer? Que histórias professoras e professores compartilham sobre as experiências vividas nos tempos de pandemia? Que práticas pedagógicas têm emergido nesse contexto? Que lições podemos aprender com as narrativas docentes?

Inspiradas em questões como essas, propusemos o projeto "Memórias da quarentena: diálogos Brasil-Peru". Antes, porém, de compartilharmos algumas narrativas 
ARAújO, M. da S.; FARIA, D. T. B. de; CELESTINO, J. M. C.; SOUSA, R. D. de.

produzidas durante os encontros, bem como as aprendizagens que nos proporcionaram, traremos os passos anteriores desta proposta.

Os diálogos entre docentes brasileiras/os e peruanas/os são partes de um projeto de pesquisa intitulado "Rede de Docentes que Narram sobre Infância, Alfabetização, Leitura e Escrita - REDEALE", que é desenvolvido na Faculdade de Formação de Professores da Universidade do Estado do Rio de Janeiro (UERJ-FFP).

Tal projeto tem como aporte teórico-metodológico a investigação narrativa e se desenvolve desde 2015, tendo como objetivo central fortalecer um modelo de formação, tensionador de lógicas e proposições inspiradas por uma racionalidade técnica aplicativa e prescritiva de pensar e fazer a formação docente e, ao mesmo tempo, reconhecer os sujeitos docentes como autoras/es e narradoras/es de sua prática (ARAÚJO, 2018, ARAÚJO, 2020; CANARIO, 2005). "Assim, temos insistido em problematizar a ideia ainda hegemônica que afirma a universidade como lugar de aprender e a escola como lugar de fazer, e os sujeitos que dela fazem parte meros implementadores de propostas verticais" (ARAÚJO, 2014, p. 31). É nesse sentido que temos buscado, em nossas pesquisas, construir um diálogo com a escola a partir das vozes de professoras/es.

Reconhecendo docentes como intelectuais que pensam e refletem sobre sua prática, elegemos três eixos articuladores para a pesquisa: o diálogo entre universidade e escola básica, a formação entre pares e a produção escrita sobre a experiência vivida (ARAÚJO, 2018).

Entendendo essas três dimensões como dispositivos de formação, dentre outras ações investigativas, construímos uma interlocução com o coletivo de docentes peruanos, denominado "Rede Desenredando Nudos" - REDENU, desde 2015. Tal interlocução foi fortalecida por meio das redes sociais e de contatos presenciais, em eventos que aconteceram tanto no Peru quanto no Brasil. Nesse percurso, os dois coletivos têm vivido um processo formativo, pautado no compartilhamento de experiências docentes, que acontece entre pares. Uma formação que favorece a reelaboração dos sentidos da prática pelos e para os próprios sujeitos e, ao mesmo tempo, desafia as/os docentes a escreverem sobre a experiência vivida.

A explosão da pandemia Covid-19 e o contexto de isolamento social por ela provocado trouxeram novas necessidades de fortalecimento das redes de partilha e discussões acerca das experiências vividas pelos dois coletivos. Assim, nasceu o projeto "Memórias da quarentena: diálogos Brasil-Peru".

O projeto se constituiu de seis encontros mensais entre os meses de abril e setembro, com duas horas de duração, pela plataforma Zoom, e teve como ponto inicial da conversa as narrativas orais das professoras que compartilharam questões de sua prática pedagógica ou vida pessoal atravessadas pela pandemia. Num segundo momento, elegeu-se uma questão orientadora para as reflexões: Como Paulo Freire responderia à pandemia? Para esse segundo momento, combinou-se, também, a produção de narrativas escritas que poderiam/deveriam explorar diferentes gêneros textuais, ou mesmo diferentes linguagens: vídeo, desenho, esquemas, charges etc. A cada encontro, foram compartilhadas quatro narrativas de cada país, comentadas por todo o grupo participante.

A média de participação foi de dezesseis brasileiras/os e dez peruanas/os. Quanto à atuação das/dos docentes, por nível de ensino, tivemos: quatro da Educação 
Infantil, seis do Ensino Fundamental, sete de Ensino Médio, um do Ensino Superior, três em outros espaços de ensino e cinco não lecionavam. Em relação à natureza das instituições de ensino, tivemos quinze da rede pública, três da rede privada e três de espaços comunitários.

Dezesseis produções brasileiras e treze produções peruanas, sendo três cartas, uma crônica, três vídeos, três poesias, dois desenhos ilustrativos, quatro fotografias, três contos, uma música, dois acrósticos e sete relatos de experiência, foram compartilhadas durante o projeto. Parte dessas narrativas foi registrada no que chamamos de diários da quarentena. Produzidas em linguagens diversas e diversos gêneros textuais, as narrativas compunham um pequeno mosaico de possibilidades de olhar para o mundo e para a escola a partir de novos questionamentos provocados pelo contexto de isolamento social.

Além do registro das narrativas nos diários da quarentena, todos os encontros foram gravados e, posteriormente, transcritos e decupados, constituindo um significativo corpus para a pesquisa, sobre o qual nos debruçamos para elaborar as primeiras reflexões sobre o processo vivido.

No presente artigo, dialogamos com as narrativas à luz de alguns referenciais, tais como Freire (1996, 2005), Rancière (2015), Pallanda (2017), Benjamin (1994) e Santos (2020), dentre outras/os, em busca de levantar algumas pistas que nos ajudem a elaborar novas compreensões, não só sobre o tempo que atravessamos, mas também para refletir sobre a potencialidade da formação entre pares na construção de alternativas político-pedagógicas para enfrentamento das situações-limites que a pandemia nos coloca.

\section{MEMÓRIAS DA QUARENTENA: NARRATIVAS DOCENTES EM DIÁLOGO}

A concepção de memória, com a qual trabalhamos aqui, se inspira nas contribuições benjaminianas ao pensar a memória na perspectiva da experiência e da narração (ACHILLES, GONDAR, 2016). As narrativas docentes sobre suas experiências pessoaisprofissionais durante o período pandêmico, memórias fragmentárias que expressam um modo de viver, escrever e guardar a história, compõem um mosaico de memórias e esquecimentos do tempo vivido e promovem um alargamento do presente. Buscamos contribuir, assim, para a invenção "de formas memória e de narração, capazes de sustentar uma relação crítica com a transmissão do passado, com o lembrar, e com a construção do futuro e o esperar" (GAGNEBIN, 2014, p. 221).

O que as narrativas docentes, produzidas no contexto da pandemia da Covid-19 e no diálogo entre docentes de dois países latino-americanos, nos ajudam a pensar sobre e como temos respondido aos desafios enfrentados no contexto atual, mas também no que se anuncia como a pós-pandemia?

Das narrativas apresentadas e comentadas pelos dois coletivos, durante o desenrolar dos cinco encontros realizados no projeto, selecionamos sete "que nos tocaram", no primeiro momento, para dialogar com elas no presente artigo, em busca de levantar algumas lições que a reflexão sobre a própria experiência pode nos trazer, como nos remete Lima, Geraldi e Geraldi (2015), inspiradas em Benjamin (1994). 


\begin{abstract}
Uma pesquisa sobre a própria experiência é sempre uma pesquisa sobre o singular. E o conhecimento singular corresponde à verdade que não se generaliza ( $p r a v d a)$, mas da qual se extraem conselhos ou lições. Ao se debruçar sobre a história, surgem inúmeras perguntas, porque não se narra qualquer coisa: o narrável se compõe do que nos tocou, nos modificou e continua carecendo de sentidos e continuará carecendo de sentidos mesmo concluída a pesquisa, porque a ele podemos retornar como já outro (p. 18).
\end{abstract}

Ouvindo, vendo, lendo, deixando-nos impactar pelas narrativas compartilhadas nos encontros, buscávamos as lições/conselhos benjaminianos, entendendo-os nas palavras do autor, no sentido de que "a natureza da verdadeira narrativa, é ter em si, às vezes de forma latente, uma dimensão utilitária...um ensinamento moral, uma sugestão prática. O conselho tecido na substância viva da existência tem um nome: sabedoria" (BENJAMIN, 1994, p. 200).

Pelas janelas da plataforma Zoom, que se abriam e fechavam a cada narrativa compartilhada nas "Memórias da Quarentena", a perplexidade e a necessidade de compartilhar sentimentos, dúvidas, indignações, saberes e não saberes, se confirmavam, convidando os dois coletivos docentes à reflexão sobre os processos vividos:

\begin{abstract}
A necessidade da partilha das aflições e desejos seja no campo educacional e, sobretudo, no campo emocional se tornaram latentes e transbordantes. Era preciso falar, era preciso narrar, era preciso compartilhar para não nos sentirmos só. Nos encontros era notório o entrelace da crise que afetava a todos. Da crise sanitária, política, social, humanitária. O encontro foi tempo da fala, falamos o que sentimos, vivemos e ansiamos, falamos em português, em espanhol, em portunhol, o que importava era narrar, narrar o vivido, a experiência. $O$ encontro também foi tempo de proposições, dentre elas a arte, o desenho, um conto, uma imagem, uma escrita. O objetivo era deixar transbordar a experiência do vivido (Diário da quarentena, Danusa, junho de 2020).
\end{abstract}

Ao longo dos encontros, fomos confirmando os impactos da pandemia no processo de desestabilização emocional, econômica e social, das populações dos dois países em diálogo, tendo visto que, no Peru, tanto quanto no Brasil, as taxas de contaminação e morte pelo vírus ocupam o topo das estatísticas latino-americanas. Temos, assim, o Brasil em terceiro lugar, em números de contaminação, atrás dos Estados Unidos e Índia; e em segundo lugar em número de mortes, no mundo, atrás apenas dos Estados Unidos; e o Peru, em relação aos países da América Latina, em quinto lugar, atrás do Brasil, Argentina, Colômbia e do México, em contaminação, porém, ficando em décimo lugar, no mundo, em número de mortos por habitantes. Em comum entre os dois países, também há denúncia sobre o descompromisso do Estado no atendimento às populações mais vulneráveis².

Não surpreende que as narrativas iniciais, além das denúncias políticas, enfatizassem o desafio de manter o equilíbrio e a saúde mental para lidar com as emoções, com o distanciamento, com a ausência das trocas e afetos, com uma nova 
administração do tempo, com a reorganização da rotina e com os medos e anseios do porvir.

Problematizando sua atuação docente frente à pandemia, no encontro realizado em abril, portanto, logo no início da implantação do isolamento, a Professora Silvia remetia-se a Freire (2005): "Cómo cambiar una educación bancária e una educación con una visión crítica del mundo en donde vivimos actualmente?" (HUACCHA, 2020, n.p.). A partir daí, a professora levantou uma série de questões que envolviam o atendimento às/aos estudantes: as crianças teriam acesso às aulas virtuais? Conseguiriam acompanhar as discussões? Que suportes de conexão os/as estudantes possuíam para se conectar com os/as docentes? Como ensinar em meio ao isolamento social obrigatório? E o papel da família no processo poderia/conseguiria ajudar? É possível praticar um ensino remoto restrito a conteúdos escolares, sem conversa, afeto ou comunicação face a face?

Preocupada mais em levantar as questões do que respondê-las, Silvia terminou sua narrativa defendendo a urgência de "una pedagogia crítica baseada en la solidariedad es tarea de todos los docentes" (HUACCHA, 2020, n.p.).

Outras narrativas docentes brasileiras e peruanas reafirmaram que um dos maiores desafios, no que tem sido chamado de ensino remoto ou virtual, é o alcance da totalidade das/os estudantes, já que uma parcela considerável delas/deles não possui acesso à internet, nem mesmo os equipamentos tecnológicos necessários para o acesso. Em muitas regiões do Peru, as "aulas" online acontecem a partir do aplicativo WhatsApp. Em outras, a rádio é o meio de comunicação, em função da ausência de redes digitais.

As perguntas de Silvia e seu esforço para ensinar de forma remota nos remeteu a Jacotot, personagem do filósofo Jacques Rancière (2005), no livro "O mestre ignorante". Jacotot é um professor exilado que se vê tendo que ensinar francês para alunos holandeses sem dominar a língua holandesa. Ao se deparar com essa realidade pouco amigável, Jacotot utiliza o livro Telêmaco, publicado em uma versão holandêsfrancês, indica a obra para os estudantes e lhes solicita que, amparados pela tradução, aprendessem o francês. O resultado da experiência foi que os estudantes se saíram muito bem, tendo apresentado um bom domínio do livro, sem qualquer apoio explicativo.

Rancière conclui que a grande lição que o mestre ensinara aos estudantes não dizia respeito aos conteúdos, mas sim a capacidade de mobilizar a própria inteligência em função do que se queira aprender. A esse processo, Rancière denomina emancipação.

Dialogando com a experiência de Jacotot, podemos refletir se o uso de aplicativos, plataformas digitais, envio de textos impressos, contribui, efetivamente, para promover um ensino que seja emancipador, no sentido dado pelo filósofo. Porém, será que essa questão só tem sentido, agora, durante a pandemia e a necessidade de isolamento? Será que, na escola, nas salas de aula presenciais, também não precisamos que nossos alunos sejam emancipados? Isso não significa que nós professoras e professores estaríamos saindo de cena e deixando o aluno conduzir seu aprendizado, mas sim mostrar que podemos aprender a pesquisar juntos, buscar juntos e criar desafios e caminhos de aprendizagem. Que possamos utilizar as aprendizagens e as 


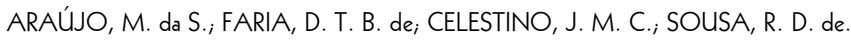

reinvenções desse período para repensar a educação que temos realizado cotidianamente nas escolas.

As narrativas compartilhadas nos encontros deixavam ecos em nossas memórias. Sendo, posteriormente, recuperadas pelas transcrições dos encontros virtuais, nos deslocaram e nos fizeram pensar na escola que temos e que queremos. Foi possível esperançar ${ }^{3}$ (FREIRE, 1992), a partir das conversas tecidas, e deixar transbordar na escrita as muitas reflexões sobre a vida, o isolamento, os anseios, o tempo, sobre esse tempo como protagonista de muitas reflexões.

O diário da quarentena de Jane, professora da Educação Infantil da rede pública de Itaboraí, nos traz essas reflexões com encantamento e poesia:

Tempo de sol, tempo de girassol

Um dia acordei e me perguntei: "Cadê o sol que foi embora e hoje não me visitou pela janela? Cadê o sol que emudeceu os pássaros e deixou o cinza que entristeceu meu dia?"

Logo, me peguei arrumando a casa, umas caixas, armários, na tentativa de me arrumar por dentro também, pois a ausência do sol coincidia com o anúncio do que estava por vir. $\mathrm{O}$ isolamento, em meio a uma pandemia.

O corpo, insistente, não entendia e ainda não entende a necessidade de ficar dentro de casa. Quer sair, quer ver o mundo, mas o mundo agora é uma tela, é por ela que vejo as notícias, que nem de longe são animadoras. Lá fora, há o medo que assusta, mas que também é protetor, ensina a cuidar. Cuidar de mim, cuidar da casa, da família, dos amigos, cuidar "das gentes" numa intensidade tamanha que a casa se transformou em uma verdadeira trincheira.

O tempo já não é mais aquele do coelho, personagem atribulado do conto de Alice no País das Maravilhas, que dizia: "estamos atrasados, estamos atrasados!". Como o coelho, vivia correndo de lá para cá, atrás do tempo perdido, vivendo os atrasos. Atrasos na produtividade, exigida pelo tempo cronometrado do relógio. Assim, precisei buscar outros modos de viver o tempo. Desacelerar os pensamentos, aquietar o coração, ser mais compreensiva comigo e com os outros.

Atravessada pelo cotidiano que se apresenta foi preciso conjugar outra vez o verbo ESPERANÇAR e encontrar em Paulo Freire muitos caminhos para continuar e seguir. É preciso pirraçar com a vida, assim procuro tudo aquilo que me faz viver os caminhos de dentro: medito para não esquecer que é preciso respirar, escrevo como ato político, para organizar o pensamento e deixar vestígios de memórias. Choro, canto alto, às vezes danço despretensiosamente pela casa. Nos guardados rememoro histórias de família, me permito peraltar com Rara, minha filha, revisito a costura, que me reaproxima de minha mãe com gosto de saudade, encontro amigos e família pelas janelas virtuais que se abrem para encontros possíveis.

As janelas virtuais, os encontros possíveis, têm me proporcionado, como professora pesquisadora, no exercício da docência, a fazer desvios. Desvios impensáveis, responsáveis, incansáveis, 


\begin{abstract}
necessários para seguir mesmo diante do cenário que se apresenta. Tenho o desafio de seguir, reinventar uma nova história para o meu fazer docente junto às professoras que comigo dividem suas trajetórias de vidaformação. Convido-as ao posicionamento político e a defender o que sabemos fazer de modos outros, como nos conclamava Paulo Freire. Este saberfazer, como potência para construirmos diálogos que nos possibilitem conjugar o esperançar com muitas vozes, esperança que não espera, mas que nos move. Foi assim com ele durante a ditadura e mesmo com todo seu cotidiano revirado, foi capaz de denunciar e anunciar a(s) histórias vividas como luta e resistência. Essas 'Pílulas Freireanas" que me acompanham já há algum tempo, têm me levado a um permanente processo de tornar-me responsável por seguir, mesmo quando o sol não aparece. Nesses dias eu planto girassóis e assim, me permito com eles "floreScer" (Diário da quarentena de Jane; 2020).
\end{abstract}

Percebemos, na narrativa de Jane, o movimento autopoiético ${ }^{4}$, que, a nosso ver, também caracteriza o processo de formação entre pares ao compartilhar conosco "o desafio de reinventar uma nova história para o meu fazer docente junto às professoras que comigo dividem suas trajetórias de vidaformação" (JANE MARCHON, 2020, n.p.)

Estudiosa do conceito de autopoiesis há duas décadas, Pallanda (2017) afirma:

Parece haver na natureza humana uma espécie de autopoiesis radical, ou seja, uma demanda profunda de autonomia de cada ser humano que teria a tarefa cósmica de construir o universo e a si mesmo. Uma tarefa voltada para a nossa condição de coautores da criação, o que é muito diferente de uma relação com o mundo onde este já está pronto e no qual nós não somos responsáveis pelo que acontece com ele (p.12).

Podemos entender, porém, que essa demanda profunda de autonomia presente na humanidade, de que nos fala a autora, em diálogo com Maturana e Varela, que mobiliza homens e mulheres para construção do universo e de si mesmo, também está presente nos coletivos docentes, que são igualmente coautores e criadores, que, na interação uns com os outros, constroem seus processos formativos, autopoieticamente.

Hortência, a professora peruana, recém-formada em Artes, que se encontra em suas primeiras experiências docentes, trouxe para o grupo uma pequena peça, esculpida em um material bem acessível, fácil de encontrar na natureza, que reproduzia a figura de Dom Quixote. A pequena estátua fora produzida por ela em busca de experimentar caminhos outros para dialogar no e com os tempos duros em que vivemos. Narrando sua produção, Hortência justificava a opção pelo personagem, em função das lições de coragem, criatividade, ética e compromisso que Dom Quixote traz consigo. No uso de material acessível para a produção da peça, a professora criava uma metáfora para explicar como as professoras peruanas vêm se reinventando para encontrar materiais didáticos e estratégias pedagógicas outras para ensinar e repensar os caminhos trilhados. 
Que lições as narrativas de Silvia, Jane e Hortência podem nos sugerir nesses tempos de isolamento social, ensino remoto e descomprometimento do poder público com a população?

Uma lição nos faz pensar novamente no movimento autopoiético, mas também nas microresistências de que nos falava Certeau (1994). Assim, diante dos impasses, de determinações, por vezes, autoritárias das instâncias superiores, as/os docentes não se colocam de forma passiva, cumprindo ordens, mas elaboram criações anônimas. Podemos ver isso nas indagações potentes de Silvia, no movimento de Jane de buscar os pares para pensar alternativas para a prática, ou mesmo no Dom Quixote de Hortência.

\section{NOVAS LIÇÕES: DIALOGANDO SOBRE A PANDEMIA INSPIRADAS PELO OLHAR DE PAULO FREIRE}

Em nossas andanças pela América Latina temos confirmado a forte presença da pedagogia freireana como um referencial primordial para a construção de uma educação emancipadora e libertadora, comprometida com os valores da solidariedade e respeito à cosmovisão dos povos originários, a ideia de comunidade.

Dialogar com o legado de Paulo Freire para buscar novas compreensões e saídas para os desafios enfrentados nos tempos de pandemia se configurou, assim, como uma fonte de inspiração e instrumento de formação para os/as docentes dos dois coletivos.

A seguir, colocamos em diálogo duas narrativas inspiradas em Paulo Freire: um acróstico, elaborado pela professora Isabel, e uma carta, produzida pela professora Alessandra.

¿Cómo respondería Freire a la pandemia?

Con la única moneda que le queda en el bolsillo compraría la palabra: Esencia

Estaría dispuesto a regresar al punto de partida sin tener miedo ni vergüenza que digan que está retrocediendo.

Sería el mejor momento de aceptar que en algo fallé y estaría dispuesto a reconocer que como ser humano tengo muchas cosas que dar.

Estaría dispuesto a crear un mundo nuevo desde aquello que a todos asusta: sin tanto para comprar, sin el carro último modelo, sin el celular de la última versión o la vacaciones en Disneylandia.

No abandonaría esta posibilidad de volver a nacer, despojado de los prejuicios de compararme si soy rico o pobre, sería la posibilidad de estar todos en las mismas condiciones y valorar la salud y la vida como el único patrimonio.

Convertiría cada día en una oportunidad de vida, de hacer algo diferente al anterior, sin la necesidad de comprar nada que no sea esencial y abrazando un sueño de vida.

Imaginaría cada día que una palabra puede convocar, que una mirada puede animar, que un paso puede encaminar, que un pan compartido puede salvar.

Armaría con los pedazos que deja esta pandemia una casa redonda donde haya lugar para todos (Diario de la cuarentena de Isabel Gutiérrez, 2020). 
O homem e seu processo de humanização é um dos grandes legados de Freire que atravessa toda a sua obra. $O$ desafio da humanização frente às realidades históricas da desumanização, da qual a crise humanitária que vivemos é um exemplo, requer que os homens compartilhem entre si seus bens materiais, políticos, culturais, simbólicos para que se possa garantir a todos e todas uma existência digna (ZITKOSKI, 2017).

Em busca do que para ela seria a essência do olhar de Freire para a pandemia, Isabel dialoga com o processo de humanização/desumanização discutido pelo educador. Ser humano, a vida como patrimônio, solidariedade, igualdade social palavras usadas para compor o seu acróstico - são "palavras verdadeiras com as quais os homens transformam o mundo" (FREIRE, 2005, p. 90) e revelam um dos sentidos que move a professora em sua ação-reflexão-ação "não é possível fazer uma reflexão sobre educação sem refletir sobre o próprio homem" (FREIRE, 2007, p. 27).

O tema que Alessandra elege para dialogar com Freire, em sua carta, está encharcado de dois sentimentos muito caros ao educador: a indignação e a amorosidade. Em sua conversa-desabafo, Alessandra nos convida a compartilhar com ela e com as/os professoras/es as angústias, as dúvidas, o sentir-se desrespeitada/o pelo poder público e pela sociedade, que tem caracterizado o exercício do magistério, especialmente, com as crianças pequenas.

Querido Paulo Freire,

Sempre senti vontade de escrever uma carta para você, para compartilhar minhas inquietações enquanto professora. Mas nunca pensei que isso se concretizaria num momento tão difícil no que se refere a saúde pública, a política e as tensões nas práticas educacionais no Brasil. Tenho a sensação de que o país virou um caos. Desde março deste ano, estamos enfrentando no Brasil, a presença de um novo vírus (covid - 19) que, de forma avassaladora, tem infectado e matado em torno de mil pessoas diariamente, provocando a necessidade de a população manter-se em isolamento social[...]

[...]Sou professora alfabetizadora, trabalho com crianças na faixa etária entre 7 e 8 anos, estudantes do primeiro segmento do Ensino Fundamental e a plataforma escolhida pela escola em que trabalho para as aulas online foi o google classroom. Por não ser da Geração $Z$, confesso que tive muitas dificuldades para realizar o cadastro dos estudantes e postar as atividades. Cada vez que acesso a plataforma, constato que estou fazendo um trabalho para "Inglês ver", já que muitas crianças não estão tendo acesso a plataforma adotada pela escola [...]

[...] Aprendi com você que "Ensinar exige bom senso" (FREIRE, 1996 p. 61). Como vou postar atividades online, sabendo que muitos dos meus alunos não têm acesso a internet de qualidade? [...]

[...] "Ensinar exige apreensão da realidade "(idem, p. 68). Que aulas serão interessantes para crianças em processo de alfabetização em plena pandemia? [...] "Ensinar exige tomada consciente de decisões" 


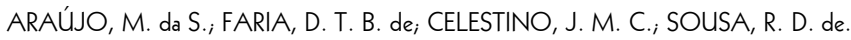

\begin{abstract}
(Idem, p. 109). E a minha decisão, neste momento, é não compactuar com a farsa e de uma educação transmissiva[...]

[...] Como percebo que a desigualdade social tem sido cada vez mais reafirmada em tempos de pandemia, defendo que "ensinar exige liberdade e autoridade" (Idem, p. 78). Não posso aceitar esta proposta de educação online como a nova normalidade, mas sim como uma grande anormalidade.

[...] "Ensinar exige intervenção no mundo" (Idem, p. 98) é por isso que essa carta é um pedido de socorro, pois preciso intervir na defesa da professora, dos/das jovens e das crianças. Porque aprendi com você que "ensinar exige a convicção que a mudança é possível" (Idem, p. 76) e por acreditar que ainda é possível reverter o caos que estamos vivenciando no momento atual, seus ensinamentos em "Pedagogia da autonomia" tem sido um alento para acreditar que juntos somos mais fortes. Obrigada por tudo!! Aprendo sempre com você!! Um abraço, Alessandra da Costa Abreu (Diário da quarentena de Alessandra Abreu, junho de 2020).
\end{abstract}

A carta da professora transborda indignação, "não compactuar com a farsa e de uma educação transmissiva" (ABREU, 2020, n.p.), porém, que não se aparta da amorosidade, "preciso intervir na defesa da professora, dos/das jovens e das crianças" (ABREU, 2020, n.p.) e se alimenta da esperança "por acreditar que ainda é possível reverter o caos que estamos vivenciando no momento atual" (ABREU, 2020, n.p.). Segundo Nita Freire (2017), para Freire, "as ações éticas genuinamente humanas nascem desses dois sentimentos indignação e amor se forem vividos intensamente em relação dialética com a esperança" (p. 223).

No diálogo com Alessandra e Isabel, uma outra lição que podemos tirar é a potência dos ensinamentos de Freire para seguir em frente, entrelaçando estratégias de ensinoaprendizagem, de luta e de resistência, estratégias que se configurem como crítico-político-pedagógicas para intervir no mundo, na sociedade, na educação, não desistindo de acreditar que "ensinar exige a convicção que a mudança é possível" (FREIRE, 1996, p. 76).

\title{
EM BUSCA DE CERRAR, PROVISORIAMENTE, ALGUMAS JANELAS E ABRIR OUTRAS:
}

A suspensão das aulas, como decorrência do isolamento social, colocou como desafios, para as redes de ensino públicas e privadas, construir alternativas que viabilizassem a manutenção do vínculo entre instituição escolar e estudantes/comunidade. A atuação docente se colocou como central nessa articulação, como também o uso da tecnologia como canal para dar conta desse desafio.

Contudo, se de um lado, a atividade remota pode se colocar como uma alternativa importante, como forma de contato com os estudantes e suas famílias, a viabilização desse contato desvela a grande desigualdade social que marca a sociedade capitalista. Uma parcela representativa da população não possui acesso à tecnologia digital, nem aos recursos materiais tecnológicos inerentes a esse acesso, como foi confirmado tanto pelas professoras peruanas, quanto pelas brasileiras, que narraram no presente artigo. 
Um outro aspecto da atividade remota abordado por vários pesquisadores, da qual não podemos nos furtar de nos remeter, mesmo que rapidamente, envolve a questão do trabalho docente (FREITAS, 2020; FRIGOTTO, 2020). Assim, Frigotto (2020) chama a atenção para dimensões da prática docente sobre as quais o trabalho remoto interfere, especialmente no que diz respeito às limitações quanto às relações interpessoais entre docentes e estudantes, que são inerentes ao contato presencial. Relações que implicam em trocas, aprendizagens, amorosidades, sociabilidades, para além do ato restrito de ensinar, relações que nos remetem a pensar o ato pedagógico como processo de humanização, como defende Freire. Essas são questões centrais para pensarmos no desdobramento da pós-pandemia, especialmente no que diz respeito ao questionamento à defesa neoliberal do ensino a distância (EAD) como projeto político para o atendimento ao direito à educação para toda a população.

O projeto "Memórias da quarentena: diálogos entre Brasil-Peru", valendo-se da tecnologia, e, nesse sentido, reafirmando o potencial desta para os enfrentamentos dos desafios que vivemos, se constituiu para os dois coletivos de docentes como um espaço de compartilhamento e de escuta. Nessa perspectiva, o projeto se colocou como instrumento potencializador do exercício de pensar tanto sobre a própria experiência quanto sobre o contexto macro, que estamos atravessando e que nos atravessa.

As narrativas de Roberta, Silvia, Jane, Hortência, Isabel, Alessandra e Danusa refletem e refratam movimentos de reflexão-ação sobre a experiência docente, se constituindo como fontes narrativas que contribuem para a construção de um conhecimento possível sobre a escola e sobre a prática pedagógica nesses tempos pandêmicos. Possibilitam-nos também reafirmar a potência da formação entre pares na construção de alternativas político-pedagógicas para enfrentamento das situaçõeslimites que a pandemia nos coloca e, quem sabe, para visualizar um inédito-viáve $f$, que se coloca no horizonte quando as questões atravessadas nas situações-limites não são percebidas como determinantes históricos, mas são transcendidas e enfrentadas.

Reafirmamos que as lições por nós extraídas nos diálogos com as narrativas de docentes brasileiras/os e docentes peruanas/os não são lições no sentido de prescrições, nem de respostas definitivas para serem reproduzidas. Retornando ao diálogo com Lima, Geraldi e Geraldi (2015), também entendemos que alguns deslocamentos são provocados em nós e algumas perguntas começam a surgir quando nos debruçamos sobre as narrativas, até porque estamos partindo de narrativas que nos tocaram e/ou tocaram essas professoras, e que se tornaram reflexão à medida em que pensamos em conjunto sobre elas e refletimos sobre seus desdobramentos.

Uma anotação do diário de quarentena de Danusa nos ajuda a concluir nossas reflexões, na perspectiva da provisoriedade que o diálogo com as narrativas provoca:

Abram as janelas, deixem o sol entrar...

Abram as janelas da vida, da alma, da esperança, da superação, da coragem, dos sonhos, do amor.

Vivamos!!! Isso tudo vai passar... por que o Cronos? Ele não para

(Diário da quarentena de Danusa; 2020). 
O apelo esperançoso da professora nos convida a olhar para o depois, para pensar de uma forma corajosa e potente os caminhos outros que a pós-pandemia demandará de nós. Caminhos e demandas que nos fazem esperançar para que as janelas da exclusão, das desigualdades sociais, da falta de acesso a uma educação de qualidade, dentre tantas outras, que impedem a produção de uma vida digna, sejam fechadas, de forma que as janelas de uma educação mais justa e humanista possam se abrir.

\section{QUARANTINE WINDOWS: LATIN AMERICAN TEACHERS'S EDUCATING EXPERIENCES}

ABSTRACT: This article aims to problematize the impacts of the pandemic context, in course, on educational policies and practices, based on the narratives of teaching collectives from two countries, articulated by a research project, in which theoretical-methodological support is the referential research-training. Placing itself in the field of narrative investigation, the research seeks to build knowledge with the teachers, which is configured both as an investigation process and as a training process. The dialogue with the teaching narratives, in the light of theoretical reflections, in particular, in the dialogue with Freire, pointed out to us the urgency of thinking about the school in the perspective of humanization and brought contributions when it comes to thinking about the training of teachers, that has been enhanced in teaching groups and in peer processes.

KEYWORDS: Narratives. Teachers. Isolation.

\section{VENTANAS DE CUARENTENA: EXPERIENCIAS DE FORMACIÓN ENTRE MAESTROS LATINOAMERICANOS}

RESUMEN: Este artículo tiene como objetivo problematizar los impactos del contexto pandémico, en curso, sobre las políticas y prácticas educativas, a partir de las narrativas de colectivos docentes de dos países, articuladas por un proyecto de investigación, cuyo sustento teórico-metodológico son los referenciales. investigación-formación. Colocándose en el campo de la investigación narrativa, la investigación busca construir conocimiento con los docentes, que se configura tanto como un proceso de investigación como un proceso de formación. El diálogo con las narrativas docentes, a la luz de las reflexiones teóricas, en particular, en el diálogo con Freire, nos señaló la urgencia de pensar la escuela en la perspectiva de la humanización y aportó aportes para pensar en la formación de docentes que grupos de enseñanza y en procesos de pares.

PALABRAS CLAVES: Conversasiones. Maestros. Aislamiento. 


\section{NOTAS}

1 - Stanley Kubrick, morto em 1998, foi um dos cineastas contemporâneos que causou a impressão de que seu desaparecimento provocou um empobrecimento das nossas expectativas estéticas e em nossa compreensão do mundo, o premiadíssimo "2001 uma odisseia no espaço" explora o desenvolvimento tecnológico acelerado entre a relação homem e máquina, ainda incipiente, e a eterna busca humana pelas origens (OROCCHIO, 2020).

2 - Até o fechamento do artigo já tínhamos no Brasil 168.989 mortos, enquanto, no Peru, foram 35.549 mortos. Fonte: https://news.google.com/covid19/map?hl=ptBR\&mid=\%2Fm\%2F016wzw\&gl=BR\&ceid=BR\%3Apt-419

3 - Não é, porém, a esperança um cruzar de braços e esperar. Movo-me na esperança enquanto luto e, se luto com esperança, espero (FREIRE, 2005, p.97).

4 - Segundo o conceito de autopoiesis, os seres vivos são autoprodutores de si mesmos, se autoorganizam de forma autônoma. As interferências que chegam de fora disparam mobilizações internas, mas não são determinantes do que lhes acontece. Por outro lado, os seres vivos são sistemas abertos às trocas externas, o que os mantêm em constante reorganização (PALLANDA, 2017).

5 - Freire aponta "que as "situações-limites" se apresentam ao homem como se fossem determinantes históricos, esmagadoras em face as quais não lhes cabe outra alternativa, senão adaptar-se", porém, se os homens chegarem a transcender a "situações-limites", é possível "descobrir ou a divisar, mais além delas e em relação com elas, o "inédito-viável" (FREIRE, 2005, p 110).

\section{REFERÊNCIAS}

ACHILLES, D., GONDAR, J. A memória sob a perspectiva da experiência. In: Estudos Interdisciplinares em Memória Social. Revista Morpheus, Rio de Janeiro, v. 9, n. 16, ago/dez 2016. Disponível em http://www.seer.unirio.br/index.php/morpheus/article/view/6055/pdf Acesso em: 21 de nov de 2020.

ARAÚJO, M. S. Com a roupa encharcada e alma repleta de chão: processos formativos entre redes e coletivos docentes. In: SANGENIS, L. F., OLIVEIRA, E., CARREIRO, H. (Orgs.). Formação de professores para uma formação plural e democrática: narrativas, saberes, práticas e políticas educativas na América Latina. Rio de Janeiro: EdUERJ, 2018.

ARAÚJO, M. S.; BAMPI, M. L. F. Estágio supervisionado, via para a pesquisa: rodas de conversas e narrativas de experiências. Revista Brasileira de Pesquisa (Auto)Biográfica, Salvador, v. 05, n.15, p. 1421 - 1434, set/dez, 2020. Disponível em: https://www.revistas.uneb.br/index.php/rbpab/article/view/7503/6856

CERTEAU. M. A Invenção do cotidiano: 1 Artes de Fazer. Ed. Petrópolis: Vozes, 2014.

FREIRE, A. M. de A. Indignação. (verbete). In:STRECK, D. R.; REDIN, E.; ZITKOSKI, J. J. (Orgs). Dicionário Paulo Freire. 3. Ed. Belo Horizonte: Autêntica Editora, 2017. 
ARAújo, M. da S.; FARIA, D. T. B. de; CELESTINO, J. M. C.; SOUSA, R. D. de.

FREIRE, A. M. de A. Pedagogia da Esperança. Um reencontro com a pedagogia do Oprimido. São Paulo: Paz e Terra, 1996.

FREIRE, A. M. de A. Pedagogia do Oprimido. 42. Ed. Rio de Janeiro: Paz e Terra, 2005.

FREIRE, A. M. de A. Educação e Mudança. 30. Ed. São Paulo: Paz e Terra, 2007.

FREITAS, L. C. de; FRAGELLA, R.; PINHO, M. L. et al. Vídeo (1h46min). Aulas remotas: é possível para todos (as) estudantes? A quem interessa? Publicado pelo Canal ANPEd Nacional, 2020.2 Disponível em: https://www.facebook.com/anped.educacao/videos/270595950977245. Acesso em: 02 jun. 2020.

FRIGOTTO, G.; LINHARES, C.; PLAISANCE, E.; et al. Vídeo (1h52min). Pandemia e póspandemia: desafios à educação. Publicado pelo Canal Waldeck Carneiro, 2020. Disponível em: https://www.facebook.com/341216022616408/videos/1070074190052901/. Acesso em: 02 jun. 2020.

GAGNEBIN, J. M. Limiar, aura e rememoração: ensaios sobre Walter Benjamin. São Paulo: Ed. 34, 2014.

HUACCHA, S. Relato de experiência para os encontros - Memórias da Quarentena: encontros entre REDEALE/ Brasil e REDENU/ Peru. Vídeo conferência, REDEALE/FFP UERJ e Escuela Campesina Alternativa, 22 jun 2020.

MORAIS, J. F. dos S.; ARAÚJO, M. S. Formação Continuada centrada na escola: Intercambiando experiências. Revista Teias, Rio de Janeiro. V.15, p.29 - 40, 2014.

NÓVOA, A. Conversas com Antonio Nóvoa: Educação em tempos de pandemia. Disponível em: https://www.youtube.com/watch?v=FNF7i_Dpflo. Acesso em: 10 de jul. de 2020.

OROCCHIO, L. Z. O cineasta das obras-primas. Revista Cult., São Paulo. Disponível em: https://revistacult.uol.com.br/home/stanley-kubrick-o-cineasta-das-obras-primas. Acesso em 16 ago. 2020.

PALLANDA, N., BOETTCHER, M., PINTO, M. Viver, conhecer na perspectiva da complexidade: Experiências de pesquisa. 1. ed. - Santa Cruz do Sul: EDUNISC, 2017.

RANCIÉRE, J. O mestre ignorante - Cinco lições sobre a emancipação intelectual. 3 ed., Belo Horizonte: Autêntica, 2015.

SANTOS. B. S. A cruel pedagogia do vírus. Coimbra: Edições Almedina. 2020. 
MATURANA, H.; VARELA, F. De máquinas e seres vivos: autopoiese - a organização do vivo. 3. ed. Porto Alegre: Artes Médicas, 1997. PIAGET, J. Biologia e conhecimento. Petrópolis, 1997.

ZITKOSKI, J. J. Humanização/desumanização. (verbete) In: STRECK, D. R.; REDIN, E.; ZITKOSKI, J. J. (orgs). Dicionário Paulo Freire. 3. Ed. Belo Horizonte: Autêntica Editora, 2017.

MaIrCE da Silva AraúJo: É mestre em Educação pela Universidade Federal Fluminense (UFF) e doutora em Educação pela Universidade Federal do Rio de Janeiro (UFRJ). Professora associada da Faculdade de Formação de Professores (FFP), da Universidade do Estado do Rio de Janeiro (UERJ). Procientista. Professora permanente do Programa de Pós-graduação em Educação: processos formativos e desigualdades sociais. Vice-líder do grupo de pesquisa Vozes da Educação: memórias, histórias e formação docente; coordenadora do grupo de pesquisa Alfabetização, Memória, Formação de professores e Relações Etnicorraciais (Almefre).

Orcid: https://orcid.org/0000-0003-1434-7796

E-mail: mairce@hotmail.com

Danusa Tederiche Borges de Faria: Mestra em Educação pelo Programa de Pósgraduação Processos Formativos e Desigualdades Sociais - PPGEDU/ UERJ.

Orcid: https://orcid.org/0000-0001-7317-8393

E-mail: danusa.tederiche@hotmail.com

Jane Marchon Cordeiro Celestino: Mestranda em Educação pelo programa de Pósgraduação da Faculdade de Formação de Professores - FFP/ Universidade do Estado do Rio de Janeiro - UERJ - Processos Formativos e Desigualdades Sociais, membro do Grupo de Pesquisa Alfabetização, Memória, Formação Docente e Relações Etnicorraciais - ALMEFRE - Pesquisa a formação de professores e suas práticas emergidas nos/dos/com cotidianos a partir das narrativas destes sobre vidaformação.

Orcid: https://orcid.org/0000-0002-3209-5847

E-mail: janemarchoncc@smail.com

Roberta Dias de Sousa: Mestra em Educação pelo Programa de Pós-graduação Processos Formativos e Desigualdades Sociais - PPGEDU/ UERJ. Interesses de pesquisa: formação docente, relações Etnicorraciais, investigação-formação, narrativas de professores, América Latina, formação docente.

Orcid: https://orcid.org/0000-0003-1137-8351

E-mail: betadias3112@gmail.com

Este periódico utiliza a licença Creative Commons Attribution 3.0, para periódicos de acesso aberto (Open Archives Iniciative - OAI).

Inter-Ação, Goiânia, v.46, n.1, p. 276-293, jan./mar. 2021. Disponível em: <http://dx.doi.org/10.5216/ia.v45i3.65120>. 